\title{
015 PP WORKING CREATIVELY TO CO-PRODUCE QUALITATIVE MENTAL HEALTH RESEARCH: REFLECTIONS FROM TWO STUDIES
}

S Carr, ${ }^{*}$ N Lambert. Department of Mental Health, Social Work and Integrative Medicine, Middlesex University, London, UK

\subsection{6/bmjopen-2017-016492.33}

This paper explores the methodological and ethical issues arising from two co-produced mental health research projects. It is a joint presentation by a practitioner researcher and a service user researcher, both of whom are leading on co-produced studies. The presentation explores issues relating to the integration of service user experiential knowledge into applied mental health research and the development of inclusive research methodologies, highlighting the inherent challenges for traditional health research methods and epistemologies. Nicky Lambert draws on her experiences of co-producing an experiential evidence base with and for women with mental and physical issues as part of her $\mathrm{PhD}$ research. She discusses the challenges of using unconventional methods in the engagement of marginalised groups in mental health research and her learning from working with 'experts by experience' as research collaborators. Sarah Carr draws on her experiences of being the principal investigator on a National Institute for Health Research School for Social Care Research funded user-led, co-produced study exploring mental health service user perspectives on targeted violence and hostility in the context of adult safeguarding. She discusses the influence and importance of methodologies and ethical approaches from mental health service user and survivor research in the project. They combine their experiences to offer good practice guidelines and suggest helpful resources. 